\title{
Pengaruh Jumlah Saluran Masuk Udara terhadap Distribusi Kecepatan Udara Pengering pada Alat Pengering Tipe Swirling Fluidized Bed
}

\section{The EFfeCt of Inlet Air Number to The Air Velocity Distribution on SWIRLING FLUIDIZED BED DRYER}

\author{
Satya Andika Putra ${ }^{1, *}$ dan Novrinaldi ${ }^{1}$ \\ ${ }^{1}$ Pusat Penelitian Teknologi Tepat Guna, Lembaga Ilmu Pengetahuan Indonesia, Jl. K.S. Tubun no.5 Subang \\ Jawa Barat, Indonesia \\ ${ }^{\star}$ Pos el: satya.andika.p@gmail.com
}

\begin{tabular}{ll}
\hline A R T I C L E I N F O & Abstract \\
\cline { 2 - 3 } $\begin{array}{l}\text { Article history } \\
\text { Received date }\end{array}$ Numerical and experimental studies have been carried out on the effect \\
13 September 2019 & of inlet air number to the air velocity distribution in the drying chamber \\
Received in revised form date & of the Swirling Fluidized Bed Dryer (SFBD). The main components of \\
24 January 2020 & SFBD are a drying chamber, plenum chamber, center body, distributor, \\
Accepted date & finite volume method on a three-dimensional model using computational \\
27 February 2020 & fluid dynamic (CFD) software. An experimental study was carried out \\
Available online date & by measuring the air velocity at eight measurement points in the drying \\
November 2020 & chamber. The results showed that using two inlet air produced a more \\
& uniform distribution of air velocity compared to one inlet air. \\
& Keywords: Drying, Swirling fluidized bed, Inlet air number, Air \\
& velocity, CFD \\
\hline Kata kunci: & Abstrak \\
\hline Pengering & Telah dilakukan kaji numerik dan eksperimental pengaruh jumlah \\
Swirling fluidized bed & Saluran masuk udara terhadap distribusi kecepatan udara pengering \\
Jumlah saluran masuk udara & pada ruang pengering alat pengeringan tipe Swirling Fluidized Bed \\
Kecepatan udara & (SFB). Alat pengeringan tipe SFB terdiri atas ruang pengering, ru- \\
CFD & ang plenum, tabung tengah (center body), distributor, saluran masuk \\
udara pengering, pemanas, dan penyuplai udara. Analisis numerik & dilakukan dengan menggunakan finite volume method pada model \\
tiga dimensi dengan bantuan perangkat lunak computational fluid \\
dynamic (CFD). Studi eksperimental dilakukan dengan mengukur \\
kecepatan udara pengering pada delapan titik pengukuran di dalam \\
ruang pengering. Hasil penelitian didapatkan bahwa dengan meng- \\
gunakan dua saluran masuk udara dihasilkan distribusi kecepatan \\
udara pengering yang lebih seragam dibandingkan dengan hanya \\
menggunakan satu saluran masuk udara.
\end{tabular}

C 2020 Widyariset. All rights reserved

\section{PENDAHULUAN}

Alat pengeringan tipe fluidisasi merupakan alat pengeringan yang masih banyak digemari oleh masyarakat untuk mengeringkan bahan berupa butiran atau biji-bijian. Menurut Devahastin (2001) pengeringan bahan berupa butiran dengan ukuran 50 s.d. $2000 \mu \mathrm{m}$ menggunakan alat pengeringan tipe fluidisasi lebih baik dibandingkan alat pengeringan tipe rotari (rotary dryer). Pengembangan alat pengeringan tipe fluidiasi terus dilakukan untuk meningkatkan kinerjanya. Salah satu pengembangannya adalah alat pengeringan tipe Swirling Fluidized Bed (SFB). Venkiteswaran dkk. (2012) menyatakan bahwa alat pengeC)2020 Widyariset. All rights reserved 
ringan tipe SFB menghasilkan kinerja pengeringan yang lebih baik dibandingkan tipe fluidisasi (fluidized bed) karena mempunyai kualitas fluidisasi yang lebih baik.

Alat pengeringan tipe SFB berbentuk tabung silinder yang terdiri atas ruang pengering dan ruang plenum yang pada bagian dalamnya terdapat tabung (center body) dan distributor (annular distributor), saluran masuk udara yang terletak pada ruang plenum, dan saluran udara keluar. Tabung bagian dalam pada ruang plenum berbentuk silinder, sedangkan pada ruang pengering berbentuk kerucut (Putra 2018). Distributor terdiri atas beberapa sudu (blade) dengan kemiringan tertentu terhadap bidang horisontal (Sreenivasan dan Raghavan 2002). Udara pengering masuk ke dalam ruang pengering melewati ruang plenum menuju distributor kemudian melewati hamparan bahan (bed) dengan sudut kemiringan tertentu sehingga akan menghasilkan kecepatan tangensial dan memberikan efek pencampuran pada bahan (Mohideen dkk. 2012).

Penelitian terdahulu tentang alat pengeringan tipe SFB telah dilakukan oleh Hafiz, Batcha, dan Asmuin (2013) dengan metode numerik. Mereka meneliti tentang pengaruh kedalaman ruang plenum dan jumlah saluran masuk udara terhadap distribusi kecepatan udara. Penelitian tentang ruang plenum secara numerik juga telah dilakukan oleh Othman, Wahab, dan Raghavan (2008). Adapun penelitian tentang ruang plenum secara eksperimental juga telah dilakukan oleh Othman dkk. (2011). Faizal dkk. (2012) dengan metode numerik meneliti tentang pengaruh jumlah dan sudut sudu distributor terhadap distribusi kecepatan udara dan rugi tekanan (pressure drop). Penelitian secara numerik tentang jumlah dan sudut sudu distributor juga telah dilakukan oleh Batcha dkk. (2013). Selain itu, Batcha dan Raghavan (2011) juga telah meneliti tentang sudut kemiringan sudu (blade) distributor secara eksperimental. Hal yang sama juga dilakukan oleh Kumar, Batcha, dan Raghavan (2011) dengan melakukan penelitian secara eksperimental tentang jumlah dan konfigurasi sudu distributor. Penelitian secara ekperimental tentang sudut kemiringan sudu distributor juga telah dilakukan oleh Simanjuntak dkk (2016).

Penelitian tentang distribusi kecepatan udara pada alat pengeringan tipe SFB perlu dilakukan untuk mendapatkan desain alat pengeringan yang optimal. Distribusi kecepatan udara pada ruang pengering akan memengaruhi kualitas fluidisasi. Penelitian terdahulu terkait dengan distribusi kecepatan udara membahas tentang distribusi kecepatan udara yang terjadi pada arah radial, yaitu kecepatan udara yang keluar sudu pada dinding tabung tengah (center body) hingga dinding tabung luar. Akan tetapi, penelitian tentang distribusi kecepatan udara yang keluar dari sudu pada ruang pengering (anulus) belum didapatkan. Penelitian ini bertujuan untuk mengetahui pengaruh jumlah saluran masuk udara terhadap distribusi kecepatan udara pada ruang pengering (anulus) alat pengeringan tipe SFB.

\section{METODE}

Penelitian dilakukan di Pusat Penelitian Teknologi Tepat Guna LIPI pada tahun 2018. Metode yang digunakan adalah numerik dan eksperimental.

\section{Numerik}

Analisis numerik menggunakan metode volume hingga (Finite Volume Method) pada model tiga dimensi dengan bantuan perangkat lunak Computational Fluid Dynamic (CFD). Metode ini digunakan untuk menyimulasikan distribusi kecepatan udara pengering pada ruang pengering 
alat pengeringan tipe SFB. Pengecekan kualitas meshing pada model tiga dimensi menggunakan metode Skewness dan Orthogonal, sedangkan model aliran udara menggunakan aliran viscous dengan model turbulensi Realizable K- $\varepsilon$ (Prabowo dkk. 2018). Persamaan Navier-Stokes diselesaikan menggunakan SIMPLE algorithm. Kondisi batas ditetapkan pada saluran masuk dan saluran keluar udara pengering dengan kecepatan udara masuk alat pengeringan sebesar $37 \mathrm{~m} / \mathrm{s}$ dan suhu udara sebesar $35^{\circ} \mathrm{C}$. Terdapat delapan titik lokasi sampel pengambilan data kecepatan udara pengering (Gambar 2). Model 3D alat pengeringan tipe SFB dapat dilihat pada Gambar 1.

Data kecepatan udara hasil simulasi pada setiap lokasi sampel diambil rata-ratanya untuk mendapatkan kecepatan udara pada setiap lokasi sampel tersebut. Kecepatan udara yang digunakan dari hasil analisis numerik (simulasi) adalah kecepatan aksial (arah vertikal) yang keluar dari sudu, kemudian dikonversi ke dalam kecepatan fluidisasi menyesuaikan sudut sudu (Persamaan 1).

$u_{u, s}=\frac{u_{u, v}}{\sin \theta}$,

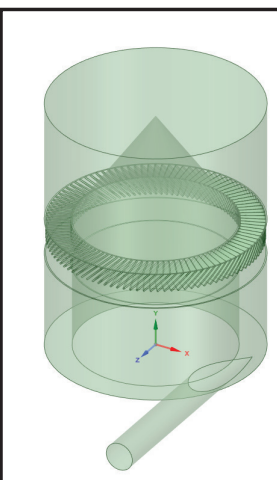

(a)

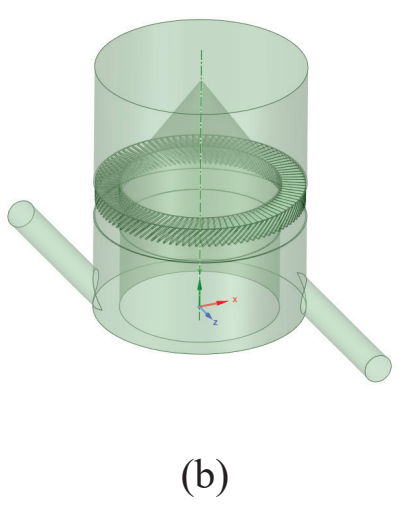

Gambar 1. Model tiga dimensi alat pengeringan tipe SFB, a. satu saluran masuk udara, b. dua saluran masuk udara. dengan,

$\mathrm{u}_{\mathrm{u}, \mathrm{s}}:$ Kecepatan udara hasil simulasi

$\mathrm{u}_{\mathrm{u}, \mathrm{v}}:$ Kecepatan udara aksial hasil simulasi

$\theta \quad: \quad$ Sudut kemiringan sudut

\section{Eksperimental}

Untuk mengetahui distribusi kecepatan udara pengering pada ruang pengering (anulus) alat pengeringan tipe SFB selain dilakukan dengan pendekatan perhitungan secara numerik juga dilakukan pengujian pada alat pengeringan tipe SFB. Alat pengeringan tipe SFB terdiri atas ruang pengering, ruang plenum, bagian selubung tengah (center body), bagian distributor, bagian saluran masuk udara pengering, bagian pemanas, dan bagian penyuplai udara. Bagian distributor tersusun dari 100 sudu dengan sudut $45^{\circ}$ dari bidang horisontal. Bagian utama alat pengeringan tipe SFB dengan dua saluran masuk udara dapat dilihat pada Gambar 3 .

Pengujian dilakukan tanpa menggunakan pemanas udara dengan memvari-

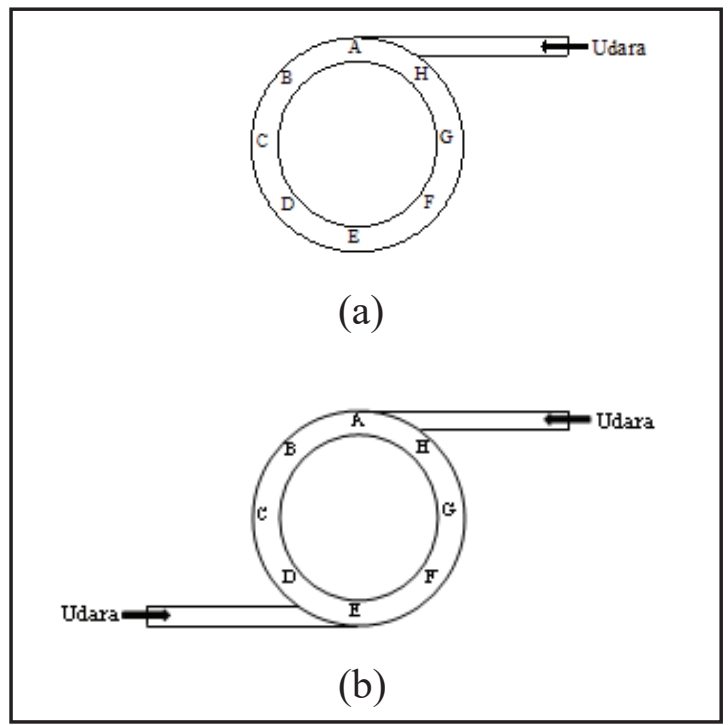

Gambar 2. Titik pengambilan data kecepatan udara hasil simulasi, a. satu saluran masuk udara, b. dua saluran masuk udara. 


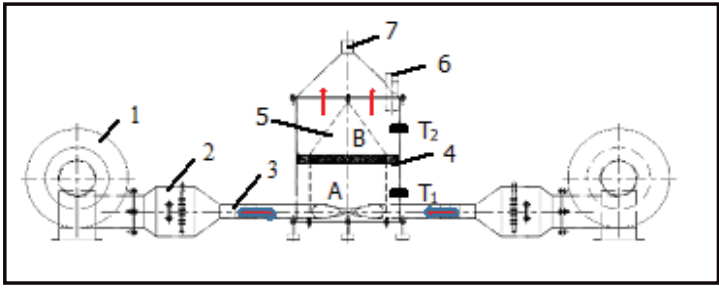

Keterangan gambar:

1. Penyuplai udara (blower)

2. Pemanas

3. Saluran udara masuk (inlet)

4. Distributor

5. Selubung tengah (center body)

6. Saluran pengumpan bahan

7. Saluran udara keluar

A. Ruang plenum

B. Ruang pengering

Gambar 3. Alat pengeringan tipe SFB dengan dua saluran masuk udara.

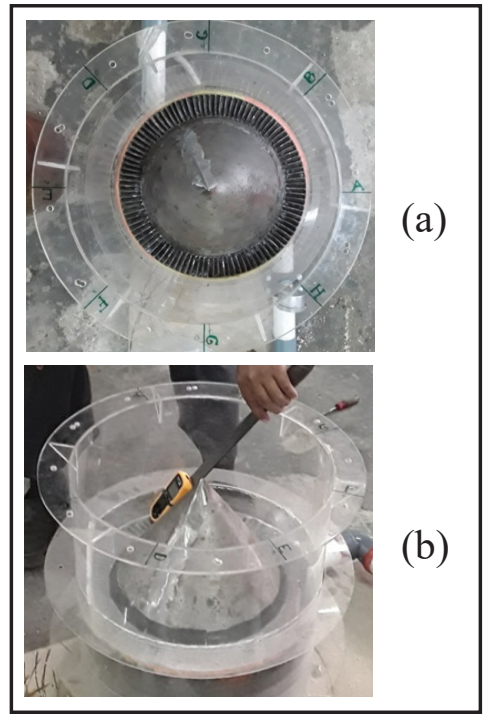

Gambar 4. Pengukuran kecepatan udara pada ruang pengering, a. Lokasi pengukuran, b. Posisi pengukuran.

asikan jumlah saluran udara, yaitu satu saluran masuk udara dengan satu unit penyuplai udara dan dua saluran masuk udara dengan dua unit penyuplai udara. Data yang diambil berupa kecepatan udara pada saluran masuk dan kecepatan udara pengering yang keluar dari distributor dengan delapan lokasi pengambilan data kecepatan sebagaimana dilakukan pada saat pengambilan data kecepatan udara dari hasil simulasi (Gambar 2). Alat ukur

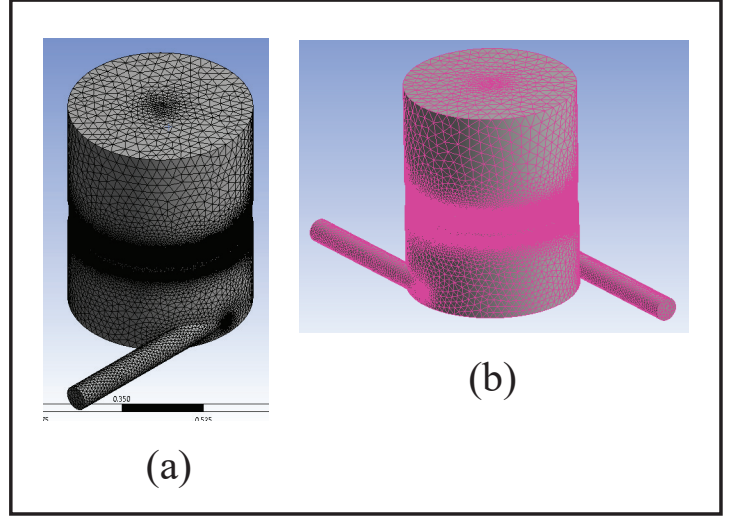

Gambar 5. Hasil meshing model alat pengeringan tipe SFB, a. satu saluran masuk udara, b. dua saluran masuk udara.

yang digunakan untuk mendapatkan data kecepatan udara adalah Anemometer. Lokasi dan posisi pengukuran kecepatan udara pada alat pengeringan tipe SFB ditunjukkan pada Gambar 4.

\section{HASIL DAN PEMBAHASAN Numerik}

Hasil meshing pada model tiga dimensi alat pengeringan tipe SFB dapat dilihat pada Gambar 5. Pengecekan kualitas meshing menggunakan metode Skewness pada model dengan satu saluran masuk udara didapatkan nilai rata-rata 0,2322 dengan simpangan baku (standar deviation) sebesar 0,1213, sedangkan pada model dengan dua saluran masuk udara didapatkan nilai rata-rata 0,2309 dengan simpangan baku sebesar 0,1206. Hal ini menunjukkan bahwa hasil kualitas proses meshing sangat baik karena nilainya masuk dalam rentang $0-0,25$. Sedangkan dengan menggunakan metode Orthogonal, hasil pengecekan kualitas meshing pada model dengan satu saluran masuk udara didapatkan nilai rata-rata 0,7664 dengan simpangan baku sebesar 0,1194, pada model dengan dua saluran masuk udara didapatkan nilai rata-rata 0,7676 dengan simpangan baku sebesar 0,1188. Hasil pengecekan kualitas 
meshing tersebut masuk ke dalam rentang nilai $0,7-0,95$ sehingga dapat disimpulkan bahwa hasil meshing baik (Fatchurrohman dan Chia 2017). Hasil meshing pada model 3D alat pengeringan ditunjukkan pada Gambar 5.

Hasil analisis numerik pada model alat pengeringan tipe SFB dengan satu saluran masuk udara menunjukkan bahwa besarnya kecepatan udara pada ruang pengering (udara keluar dari sudu) tidak seragam. Hal ini dapat diketahui dari hasil simulasi kecepatan udara pada Tabel 1 .

Kecepatan udara yang paling besar terjadi pada lokasi E sedangkan kecepatan udara terendah terjadi pada lokasi $\mathrm{C}$ dengan selisih kecepatan udara sebesar 5,76 m/s.

Di sisi lain pada model alat pengeringan tipe SFB dengan dua saluran masuk udara didapatkan bahwa kecepatan udara yang paling besar terjadi pada lokasi G, sedangkan kecepatan udara terendah terjadi pada lokasi $\mathrm{H}$ dengan selisih kecepatan udara sebesar 2,78 m/s (Tabel 2).

Sebaran data kecepatan udara dapat dilihat secara jelas pada Gambar 6. Dari grafik perbandingan kecepatan udara pada alat pengeringan tipe SFB dengan satu saluran udara dan dua saluran udara tersebut dapat diketahui bahwa data kecepatan udara dengan menggunakan dua saluran masuk udara dihasilkan distribusi kecepatan udara

Tabel 1. Kecepatan udara hasil analisis numerik pada ruang pengering alat pengeringan tipe SFB dengan satu saluran masuk udara.

\begin{tabular}{cc}
\hline Titik Lokasi & Kecepatan udara $(\mathrm{m} / \mathrm{s})$ \\
\hline A & 4,36 \\
\hline B & 2,53 \\
\hline C & 2,02 \\
\hline D & 5,21 \\
\hline E & 7,78 \\
\hline F & 6,30 \\
\hline G & 6,75 \\
\hline H & 4,74 \\
\hline
\end{tabular}

Tabel 2. Kecepatan udara hasil analisis numerik pada ruang pengering alat pengeringan tipe SFB dengan dua saluran masuk udara.

\begin{tabular}{cc}
\hline Titik Lokasi & Kecepatan udara $(\mathrm{m} / \mathrm{s})$ \\
\hline A & 8,23 \\
\hline B & 7,76 \\
\hline C & 6,83 \\
\hline D & 8,31 \\
\hline E & 9,00 \\
\hline F & 7,23 \\
\hline G & 9,12 \\
\hline H & 6,34 \\
\hline
\end{tabular}

pada ruang pengering yang lebih seragam dibandingkan dengan hanya menggunakan satu saluran masuk udara. Hal ini dapat dibuktikan berdasarkan statistika dengan menghitung nilai koefisien keragaman (coefficient of variation) (Triola 2010). Kecepatan udara hasil simulasi menggunakan dua saluran masuk udara mempunyai nilai koefisien keragaman yang lebih kecil yaitu $0,119 \%$ dibandingkan hanya menggunakan satu saluran masuk udara yaitu sebesar 0,377\%. Nilai koefisien keragaman dapat digunakan untuk mengetahui tingkat keragaman (variasi) data, makin kecil nilainya, maka menunjukkan bahwa sebaran data makin merata (Yusniyanti dan Kurniati 2017).

\section{Eksperimental}

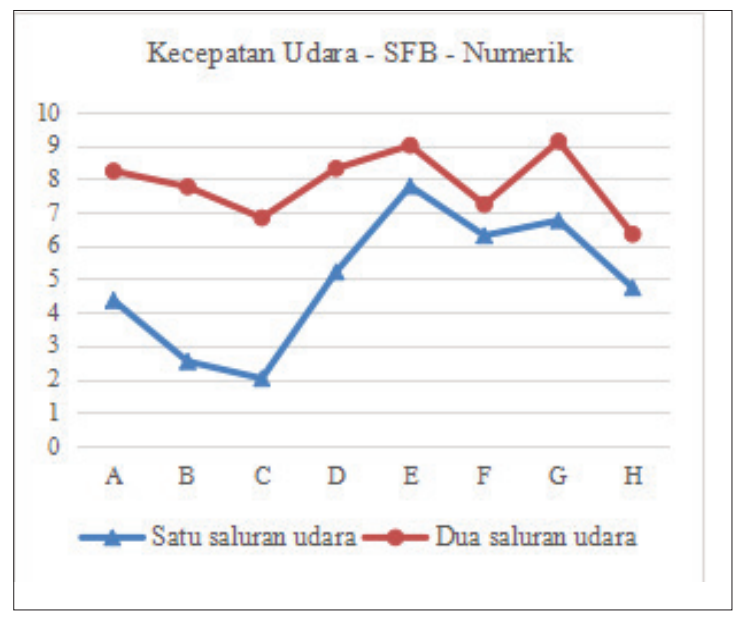

Gambar 6. Perbandingan kecepatan udara hasil analisis numerik pada ruang pengering alat pengeringan tipe SFB dengan satu saluran masuk udara dan dua saluran masuk udara. 
Hasil pengukuran kecepatan udara pada ruang pengering alat pengeringan tipe SFB dengan satu saluran masuk udara (Tabel 3) didapatkan bahwa kecepatan udara tertinggi terjadi pada lokasi E, sedangkan yang terendah terjadi pada lokasi $\mathrm{D}$ dengan selisih $6,03 \mathrm{~m} / \mathrm{s}$.

Sementara itu, pengukuran kecepatan pada alat pengeringan tipe SFB dengan dua saluran masuk udara (Tabel 4) didapatkan bahwa kecepatan udara kecepatan udara tertinggi pada lokasi $\mathrm{E}$ dan terendah pada lokasi $G$ dengan selisih kecepatan udara sebesar $3,56 \mathrm{~m} / \mathrm{s}$.

Untuk mengetahui secara jelas sebaran data kecepatan udara hasil pengukuran, pada Gambar 7 ditampilkan grafik perbandingan kecepatan udara hasil pengukuran pada ruang pengering alat pengeringan tipe SFB dengan satu saluran masuk udara dan dua saluran masuk udara. Pada grafik tersebut dapat diketahui bahwa pada alat pengeringan tipe SFB dengan dua saluran masuk udara menghasilkan kecepatan udara yang lebih seragam. Pernyataan ini dapat dibuktikan berdasarkan statistika yaitu nilai koefisien keragaman data kecepatan udara hasil pengukuran pada ruang pengering tipe SFB dengan dua saluran masuk udara sebesar $0,137 \%$. Nilai tersebut lebih kecil dibandingkan hanya menggunakan satu saluran masuk sebesar $0,375 \%$.

Tabel 3. Kecepatan udara hasil pengukuran pada ruang pengering alat pengeringan tipe SFB dengan satu saluran masuk udara.

\begin{tabular}{cc}
\hline Titik Lokasi & Kecepatan udara $(\mathrm{m} / \mathbf{s})$ \\
\hline A & 4,60 \\
\hline B & 4,27 \\
\hline C & 2,90 \\
\hline D & 2,80 \\
\hline E & 8,83 \\
\hline F & 7,13 \\
\hline G & 6,47 \\
\hline H & 5,60 \\
\hline
\end{tabular}

Distribusi kecepatan udara pengering pada ruang pengering akan berpengaruh pada kualitas fluidisasi yang kemudian akan memengaruhi laju pengeringan suatu bahan pada saat proses pengeringan. Apabila distribusi kecepatan udara tidak seragam maka diperkirakan ada lokasi (titik) yang kecepatan udaranya lebih rendah daripada kecepatan minimum fluidisasi sehingga bahan akan jatuh sesaat. Hal ini akan memengaruhi proses perpindahan panas dan massa pada bahan yang pada akhirnya akan mempengaruhi laju pengeringan pada saat proses pengeringan.

\section{KESIMPULAN DAN REKOMENDASI}

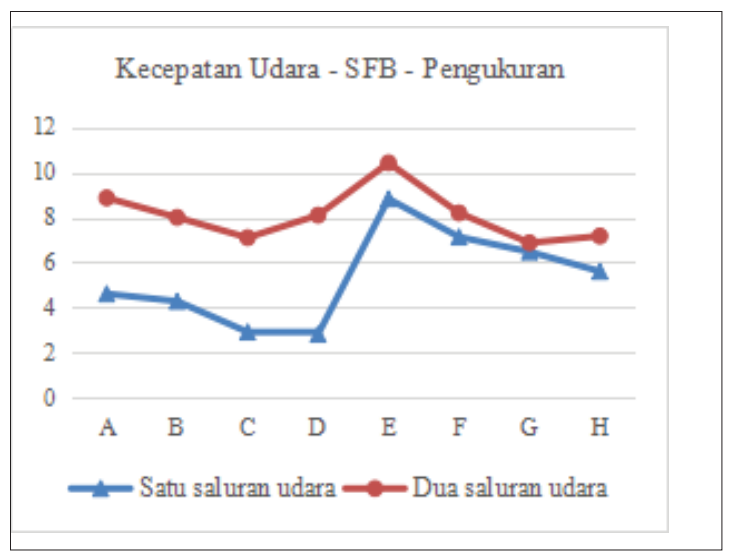

Gambar 7. Perbandingan kecepatan udara hasil pengukuran pada ruang pengering alat pengeringan tipe SFB dengan satu saluran masuk udara dan dua saluran masuk udara.

Tabel 4. Kecepatan udara hasil pengukuran pada ruang pengering alat pengeringan tipe SFB dengan dua saluran masuk udara.

\begin{tabular}{cc}
\hline Titik Lokasi & Kecepatan udara $(\mathrm{m} / \mathrm{s})$ \\
\hline A & 8,87 \\
\hline B & 8,00 \\
\hline C & 7,10 \\
\hline D & 8,10 \\
\hline E & 10,43 \\
\hline F & 8,20 \\
\hline G & 6,87 \\
\hline H & 7,17 \\
\hline
\end{tabular}




\section{Kesimpulan}

Hasil kaji numerik dan eksperimental menyatakan bahwa jumlah saluran masuk udara pada alat pengeringan tipe SFB berpengaruh pada distribusi kecepatan udara di ruang pengering. Alat pengeringan SFB dengan dua saluran masuk udara menghasilkan distribusi kecepatan udara yang lebih seragam di ruang pengering dibandingkan dengan hanya menggunakan satu saluran masuk udara.

\section{Rekomendasi}

Perlu dilakukan penelitian secara eksperimental proses pengeringan suatu bahan dengan memvariasikan jumlah saluran masuk udara untuk mengetahui pengaruh jumlah saluran udara masuk terhadap laju pengeringan suatu bahan.

\section{UCAPAN TERIMA KASIH}

Terima kasih kepada Kementerian Riset, Teknologi dan Pendidikan Tinggi yang telah memberikan dana penelitian dalam program Karyasiswa Pendidikan Gelar Pascasarjana dan juga kepada Pusat Penelitian Teknologi Tepat Guna LIPI yang telah memberikan dana dan penggunaan fasilitas penelitian.

\section{DAFTAR ACUAN}

Batcha, M F M, dan Vijay R Raghavan. 2011. "Experimental Studies on a Swirling Fluidized Bed with Annular Distributor." Journal of Applied Sciences 11 (11): 1980-86.

Batcha, Mohd Faizal Mohideen, Mohd AlHafiz Mohd Nawi, Shaharin Anwar Sulaiman, dan Vijay R Raghavan. 2013. "Numerical Investigation of Air Flow in a Swirling Fluidized Bed." Asian journal of Scientific Research 6 (2): 157-66.

Devahastin, Sakamon. 2001. Panduan Praktis Mujumdar untuk Pengerin- gan Industrial. Bogor: IPB Press.

Faizal, Mohd, Suzairin Seri, Sh Ezamuddin, dan Vijay R Raghavan. 2012. "Numerical Investigation of Air Flow Distribution in a Swirling Fluidized Bed." Advance Material Research 499: 132-37.

Fatchurrohman, N, dan S.T Chia. 2017. "Performance of Hybrid Nano-Micro Reinforced mg Metal Matrix Composites Brake Calliper: Simulation Approach." Dalam $4^{\text {th }}$ International Conference on Mechanical Engineering Research (ICMER2017), 257:1-7. Swiss Garden Beach Resort, Kuantan, Pahang: IOP Conf. Series : Materials Science and Engineering. https://doi.org/10.1088/1757899X/257/1/012060.

Hafiz, M A, M F M Batcha, dan N Asmuin. 2013. "Effect of Plenum Chamber Depth in a Swirling Fluidized Bed." Materials Science and Engineering 50: $1-7$.

Kumar, V. Vinod, M.F Batcha, dan V.R Raghavan. 2011. "Study of Fluid Dynamic Performance of Distributor Type in Torbed Type Reactors." Engineering E-Transaction 6 (1): 70-75.

Mohideen, Mohd Faizal, Binod Sreenivasan, Shaharin Anwar Sulaiman, dan Vijay Raj Raghavan. 2012. "Heat Transfer in Swirling Fluidized Bed with Geldart Type-D Particles." Korean J. Chem. Eng. 29 (7): 862-67.

Othman, Safiah, Normayati Nordin, Abas A Wahab, dan Vijay R Raghavan. 2011. "Experimental Study of Flow in a Plenum Chamber of a Swirling Fluid Bed." Dalam 2nd International Conference on Mechanical Engineering (ICME2011). Putrajaya, Kuala Lumpur, Malaysia: UTHM.

Othman, Safiah, Abas A Wahab, dan Vijay $\mathrm{R}$ Raghavan. 2008. "Numerical 
Study of the Plenum Chamber of a Swirling Fluidized Bed." Manufacturing Engineering, 6.

Prabowo, Djatmiko Ichsani, Wawan Aries Widodo, dan Melvin Emil Simanjuntak. 2018. "Experimental and Numerical Study of Coal Swirl Fluidized Bed Drying on Different Angle of Guide Vane." Dalam AIP Conference Proceedings, 1983:1-10. 020021. American Institute of Physic.

Putra, Satya Andika. 2018. "Perancangan Alat Pengering Gabah Tipe Swirling Fluidized Bed Skala Laboratorium." Tesis, Bandung: Institut Teknologi Bandung.

Simanjuntak, Melvin Emil, Djatmiko Ichsani, Wawan Aries Widodo, dan Ahmad Sefriko. 2016. "Experimental Study The Effect of Angle of Blade Inclination on Coal Swirl Fluidized Bed Drying." ARPN Journal of Engineering and Applied Sciences 11 (2): 1004-1009.

Sreenivasan, Binod, dan Vijay R Raghavan. 2002. "Hydrodynamics of a
Swirling FLuidised Bed." Chemical Engineering and Processing, 8.

Triola, Mario F. 2010. Elementary Statistics. 11th ed. USA: Addison-Wesley.

Venkiteswaran, Vinod kumar, Goo Jia Jun, Chin Yee Sing, Shaharin Anwar Sulaiman, dan Vijay R Raghavan. 2012. "Variation of Bed Pressure Drop with Particle Shapes in Swirling Fluidized Bed." Journal of Appllied Sciences 12 (24): 2598-2603.

Yusniyanti, Erna, dan Kurniati. 2017. "Analisa Puncak Banjir dengan Metode MAF (Studi Kasus Sungai Krueng Keureuto)." Jurnal Einstein 5 (1): 7-12. https://doi.org/10.24114/ einstein.v5i1.7224. 